\title{
Quebec Cooperative Study of Friedreich's Ataxia
}

\section{Effect of a Valine Load Test on Plasma Alpha-Keto Acids in Friedreich Ataxia}

\author{
A. BARBEAU (1), M. BERTRAND (2), R. BOUCHARD (3), G.L. GAUTHIER (2), J.P. BOUCHARD (3)
}

SUMMARY: To test the physiological significance in vivo of our previous in vitro finding of reduced valine dehydrogenase (VDH) activity in patients with Friedreich's Ataxia, we subjected ataxic patients and controls to an oral valine load test $(1.0 \mathrm{~g})$ and measured the levels of branched chain $\alpha$-keto acids in the plasma for 24 hours. We demonstrated a significantly higher peak for $\alpha$-keto isovaleric acid in

RÉSUMÉ: Afin de vérifier la signification physiologique in vivo de nos trouvailles antérieures qui indiquaient, in vitro, que l'activité de l'enzyme valine déshydrogénase (VDH) était diminuée dans l'Ataxie de Friedreich, nous avons soumis des patients ataxiques et des témoins $\dot{a}$ un test de surcharge orale en valine et avons mesuré le niveau plasmatique des acides $\alpha$. cétoniques $a$ chaîne latérale pendant 24 heures. Nous avons démontré une élévation significative du taux d'acide $\alpha$.
Friedreich's Ataxia and a general trend towards higher than control values in all other $\alpha$-keto acids measured, and at all times in the experiment. These changes are compatible with the postulated defect in regulation of the activity of $\mathrm{VDH}$ in this illness, but because of their small amplitude, they also indicate that a VDH deficiency is not the genetic defect in Friedreich's Ataxia.

cétoisovalérique au moment du pic chez ces patients, ainsi qu'une tendance généralisée à la hausse pour tous les autres acides $\alpha$ cétoniques, et ce à tous les moments de l'expérience. Ces modifications sont compatibles avec la présence d'une déficience régulatoire dans l'activité du $V D H$, mais leur faible amplitude signifie qu'un bloc de l'activité du VDH n'est pas le défaut génétique primaire dans l'ataxie de Friedreich.
From the Clinical Research Institute of Montreal (1), The Department of Chemistry, University of Montreal (2), and the Hôpital de l'Enfant-Jésus, Quebec City (3).

Reprint requests for the complete supplement on Friedreich"s Ataxia (Phase Three, Part Two) to: Prof. Andre Barbeau, Clinical Research Institute of Montreal, 110 Pine Avenue West, Montreal, Quebec, Canada, H2W IR7.

\section{INTRODUCTION \\ In previous studies from our} laboratories we had shown that valine dehydrogenase (VDH) activity in leukocytes of patients with Friedreich's Ataxia was significantly decreased, but not in all subjects (Barbeau et al, 1982, this issue). Interestingly, systematic profiling of blood and urine $\alpha$-keto acids equally revealed significant blood increases in $\alpha$-keto isovaleric acid, $\alpha$ keto 3-methyl valeric acid and $\alpha$-keto glutaric acid accompanied by significant increases in the urinary concentration of the first two keto acids. (Bertrand et al, 1982, this issue). Thus in vitro data coincided with in vivo data to implicate a slow-down in the activity of the VDH enzyme in some patients with Friedreich's Ataxia.

Such impairment in enzyme activity is best revealed in vivo under metabolic stress conditions, such as an oral load of the precursor. Similarly these loading studies help in understanding the role of metabolic intermediates which may accumulate under this conditions and cause toxic damage. We therefore undertook to investigate in our patients, and suitable control subjects, the biochemical changes in the concentration of plasma $\alpha$-keto acids induced by an oral load of valine. In the presence of a primary block in enzyme activity, one would expect a marked increase of the metabolities immediately preceding the block.

\section{SUBJECTS AND METHODS}

Seven patients with typical Friedreich's Ataxia as defined by Geoffroy et al, (1976) participated in this study after informed consent. Five of the patients originated from the Rimouski isolate (Bouchard et al, 1979) and two from the Montreal area. 
The average age of the ataxic subjects was 25.2 years; 4 were women, 3 men. The mean duration of their illness was 16.4 years, and all were Grade 4 severity according to the scale of Pourcher and Barbeau (1980). Three patients ( 2 men, one woman, average age 29.3 years) with the recessive spastic ataxia of Charlevoix-Saguenay (Bouchard et al, 1978) were also studied. Five normal control subjects ( 3 women, 2 men; average age 24.5 years) participated in exactly the same protocol. All subjects were subjected to a control diet for a minimum period of 2 days before the test. This diet was calculated to contain on the average 2100 calories (lipids $100 \mathrm{~g}$; glucides $300 \mathrm{~g}$; proteins $100 \mathrm{~g}$ ). Despite these efforts at normalization, valine content of the diet actually consumed was calculated to vary from 1.6 to $2.9 \mathrm{~g}$ in the ataxic subjects (mean $2.42 \mathrm{~g} /$ day) and from 2.9 to $4.23 \mathrm{~g}$ (mean 3.75 $\mathrm{g} /$ day) in the control subjects.

On the day of the experiment, patients and controls fasted from midnight. At 08:00 hrs, an intravenous solution of $0.45 \% \mathrm{NaCl}$ in $1000 \mathrm{ml}$ (flow rate $100 \mathrm{ml} / \mathrm{hr}$ ) was installed until the end of the first part of the experiment 6 hours later. After the 4th hour, the subjects were allowed to eat the controlled diet and then rested until 08:00 the next morning. Blood samples were collected at times $0,1,2,4,8$ and 24 hours and immediately centrifuged at $0^{\circ} \mathrm{C}$ at $3500 \mathrm{rpm}$. There were preserved at $-35^{\circ} \mathrm{C}$ until analysis. In two patients and one control subject, samples were only obtained at 0,1 and 2 hours. At time 0 , all subjects were given $1.0 \mathrm{~g}$ of valine by mouth in gelatine capsules.

\section{Sample Preparation}

All reagents and solvents were of analytical grade. Solvents were redistilled before use. All $\alpha$-keto acids as well as 1,2-diaminobenzene dihydrochloride were obtained from Sigma Chemicals (St-Louis, Mo., U.S.A.). Silylating reagents such as $\mathbf{N}$ methyl-N-trimethyltrifluoro-acetamine (MSTFA), trimethylchlorosilane (TMCS) and silylation grade pyridine were from Pierce (Rockford, Il., U.S.A.). Pure quinoxalinol standards were prepared by reaction of the appropriate $\alpha$-keto acid with 1,2 diaminobenzene as described by Morrison (1954).

Untreated plasma sample are defrozen and a $0.50 \mathrm{~mL}$ aliquot is placed in a screw capped test tube with $100 \mathrm{uL}$ of the internal standard solution (1mM $\alpha$-ketovaleric acid in $2 \mathrm{~N} \mathrm{HC1)}$ and $500 \mathrm{uL}$ of a freshly prepared $1 \%$ solution of 1,2 diaminobenzene dihydrochloride in $\mathrm{HCl} 2 \mathrm{~N}$ is added. The tube is then incubated for 1 hour at $70^{\circ} \mathrm{C}$ on an aluminum bloc. After this period of time, the formation of the quinoxalinol derivatives of the $\alpha$-keto acids is quantitative (Bertrand et al, 1982, this issue).

The sample is cooled and the $\mathrm{pH}$ adjusted to 1.0 with addition of $2 \mathrm{~g}$ of ammonium sulfate in order to optimize recovery yields. The solution is then extracted with $5 \mathrm{~mL}$ of ethyl acetate for 10 minutes on an Eberback mechanical agitator. After centrifugation at 3000 $\mathrm{rpm}$ for 5 minutes, the organic layer is carefully transferred into a clean dry reaction tube and evaporated to dryness under a stream of nitrogen (99.99 Zero, gas Cryogas, Montreal, Canada). The dry residue is then taken up in $50 \mathrm{uL}$ of pyridine to which $50 \mathrm{uL}$ of MSTFA containing $1 \%$ TMCS is added and the mixture sealed under nitrogen is incubated for 30 minutes at $70^{\circ} \mathrm{C}$. The sample is then ready for gaschromatographic analysis.

\section{Gas Chromatography}

All analyses were performed using a Perkin-Elmer Sigma 2B gas chromatograph equipped with a flame ionisation detector (FID). The chromatographic conditions were as follows: a 25 meter (0.23 mm I.D.) WCOT capillary column (PerkinElmer, Norwalk, Conn. U.S.A.) coated with methyl silicone (OV - 101) was maintained at $120^{\circ} \mathrm{C}$ for 2 minutes, then programmed at $8^{\circ} \mathrm{C} / \mathrm{min}$ to a final temperature of $240^{\circ} \mathrm{C}$ and held for 10 minutes. The reaction mixture was injected using a Perkin-Elmer all glass split/splitless injector operated in the split mode. The capillary injector contains a glass liner packed with silanized glass beads. This precolumn ensures complete vaporisation and mixing with the carrier gas prior to splitting and also traps undesirable substances before they reach the column. During all analyses the precolumn flow was $20 \mathrm{~mL} / \mathrm{min}$ giving a $2 \mathrm{~mL} / \mathrm{min}$ flow through the column and a split ration of $9: 1$. The make up gas $\mathrm{He}$ was $30 \mathrm{~mL} / \mathrm{min}$ and $\mathrm{H}_{2}$ and air at the detector were respectively 30 and $450 \mathrm{~mL} / \mathrm{min}$.

Data acquisition and reduction was effected by the use of Sigma 15 data station linked to the chromatograph and computerized reports of analysis were obtained using the internal standard method. This procedure has been calibrated against a mass spectrometric method (Bertrand and Gauthier, 1982, in preparation).

\section{RESULTS AND DISCUSSION}

The detailed results of these studies are given in Table 1 and illustrated graphically in Figures 1 to 4 . It can be seen that the only significant difference, in this small sample, at time zero, is an increase in the concentration of $\alpha$-keto isovaleric acid, the metabolite of valine, in Friedreich's Ataxia, two hours after valine. This confirms previous findings in that disease (Bertrand et al, 1982, this issue). The small trends however are more significant in view of the lower valine intake by patients during the previous two days. After a valine load, plasma pyruvate falls in all three groups for 4 hours, and rose rapidly to control values after the subjects broke the fast (Fig. 1). No significant differences were noted between the various study groups. $\alpha$-ketoisovaleric acid (KIVAL) increased significantly (Fig. 2) two hours after the valine load and remained higher than control values throughout the experiment.

As expected, the increase in $\alpha$ KIVAL competitively inhibited the formation of the metabolites of the other branched chain amino acids: $\alpha$ keto methyl-valeric acid ( $\alpha$-KMVAL) and $\alpha$-ketoisocaproic acid ( $\alpha$ KICAP), since the same enzyme apparently handles all three amino acids. In Fig. 3 it can be seen that after an initial drop, $\alpha$-KMVAL increases rapidly. The levels for the Friedreich's patients remain higher, at all points, than those of the controls without reaching statistical significance. One 


\section{TABLE I}

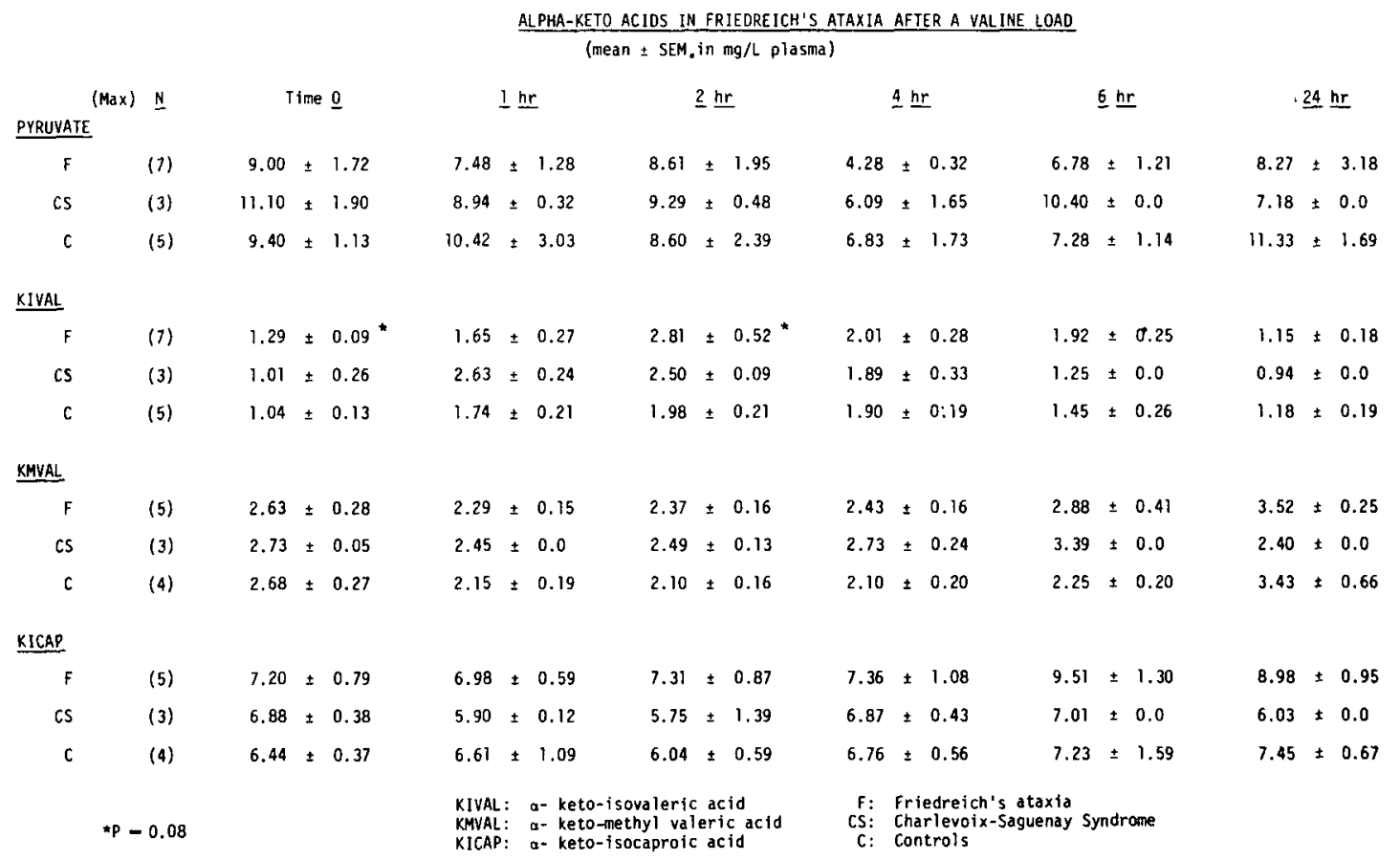

Load test: I gram of Valine p.o.

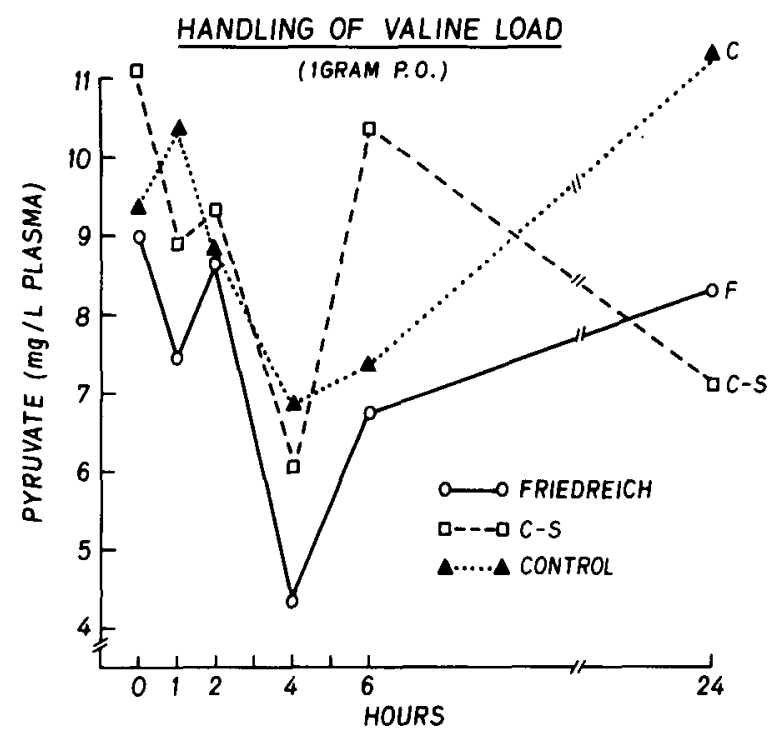

Figure 1 - Effect of a valine load $(1.0 \mathrm{~g}$, oral) on plasma levels of pyruvate. Three groups of subjects are studied: normal controls, patients with the Charlevoix-Saguenay syndrome of spastic ataxia and patients with typical Friedreich's Ataxia. The same three groups will be used throughout figs. 2-4.

\section{HANDLING OF VALINE LOAD}

(IGRAM P. O.)

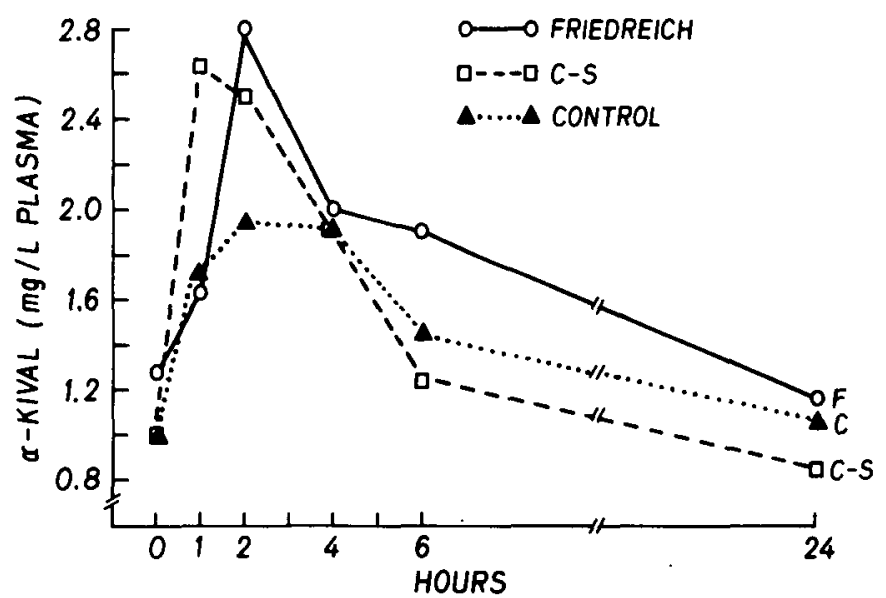

Figure 2 - Effect of a valine load on plasma levels $\alpha$-keto isovaleric acid ( $\alpha-\mathrm{KMVAL})$. 


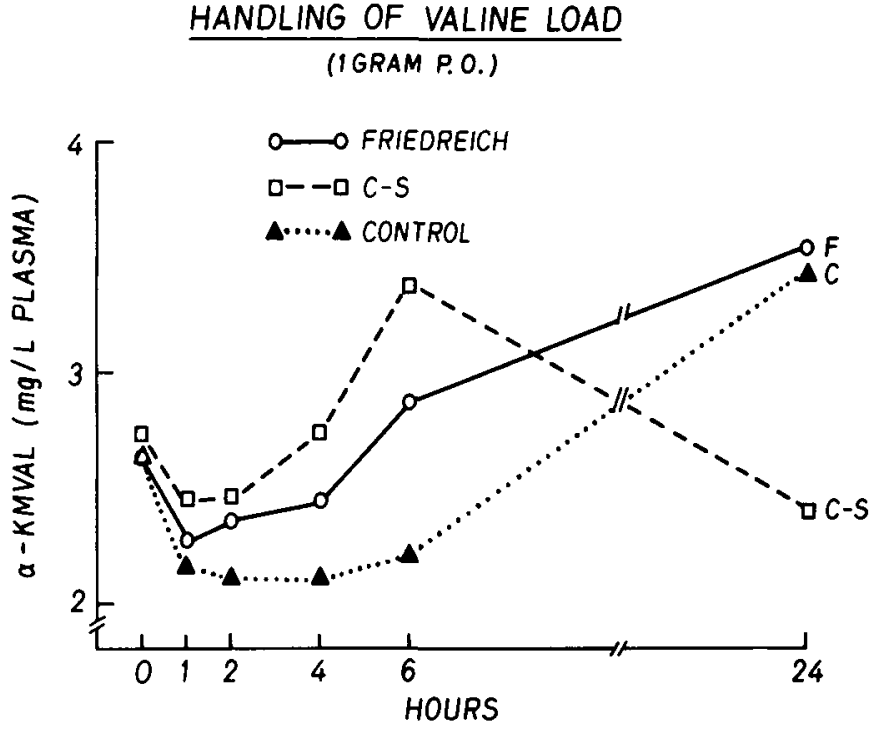

Figure 3 - Effect of valine load on plasma levels of $\alpha$-keto-methyl valeric acid $(\alpha-\mathrm{KMVAL})$.

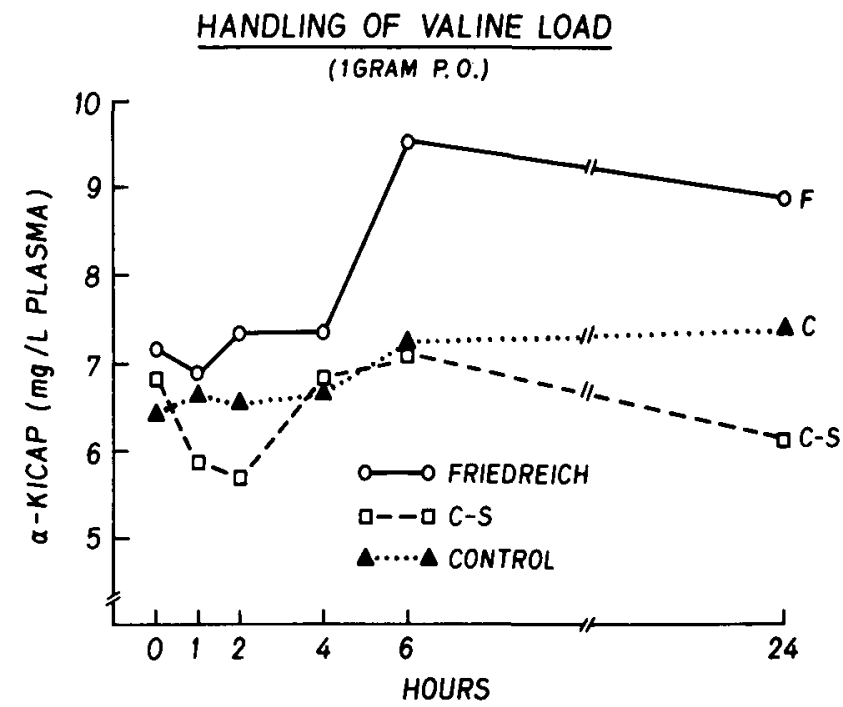

Figure 4 - Effect of valine load on plasma levels of $\alpha$-keto-isocaproic acid ( $\alpha$-KICAP). striking variation is the marked increase in $\alpha$-KICAP levels in Friedreich's Ataxia as soon as eating is resumed. (Fig. 4).

In summary, these in vivo experiments are compatible with a slow-down in the activity of branchedchain amino acid dehydrogenage as previously demonstrated in vitro by us (Barbeau et al, 1982, this issue), and with the findings in plasma $\alpha$-keto acids reported by Bertrand et al, (1982, this issue). On the other hand, it is also evident that the block in this enzyme, particularly its valine dehydrogenase (VDH) version, can only be partial in these patients with Friedreich's Ataxia, since the elevation of immediate precursors of the enzyme is minimal although significant, particularly when a meal is taken 4 hours after the load in valine. It is thus likely that the deficiency in VDH activity, when present, is only secondary to a regulatory defect and not to the genetic block in Friedreich's Ataxia; a genetic block, such as the one in Maple Syrup
Urine disease would have resulted in much higher levels of $\alpha$-keto acids in the plasma. A previously stated (Barbeau et al, 1982, this issue) elevated circulating levels of these branched-chain keto acids for long periods after meals could contribute to the inhibition of a number of other enzyme systems, particularly $\mathrm{PDH}$ and glutamic acid decarboxylase (GAD), the latter important in the formation of gamma-amino-butyric acid (GABA). It would be useful to test various forms of recessive ataxias under similar experimental conditions, and after oral loads in leucine as well as isoleucine, respectively.

Finally the impairment in VDH activity should be compared to that of $\mathrm{PDH}, \alpha \mathrm{KGDH}$, and GDH previously demonstrated in Friedreich's Ataxia, and a search for a common factor should be made. As will be seen elsewhere in this issue, this common factor could perhaps be the composition of the mitochondrial membrane.

\section{ACKNOWLEDGEMENTS}

The studies reported in this paper were supported by grants from l'Association canadienne de l'Ataxie de Friedreich and the $O$. Malette Foundation of the Hottel-Dieu Hospital. The authors would like to thank Miss Suzanne Paris for nursing assistance and Mrs. Hélène L. Crête for typing the manuscript. Miss S. Simard supervised the dietary control of the patients.

\section{REFERENCES}

BARBEAU, A., PATENAUDE, F., NADON, G., CHARBONNEAU, M. and CLOUTIER, T. (1982). A possible genetic pattern of taurine urinary excretion in Friedreich's Ataxia. Can. J. Neurol. Sci., this is sue.

BERTRAND, M., BOUCHARD, R., GAUTHIER, G.L., BOUCHARD, J.P. and BARBEAU, A. (1982). Quantitative metabolic profiling of $\alpha$-keto acids in Friedreich's Ataxia. Can. J. Neurol. Sci., this issue.

BOUCHARD, J.P., BARBEAU, A., BOUCHARD, R., PAQUET, $M$. and BOUCHARD, R.W. (1979). A cluster of Friedreich's Ataxia in Rimouski, Quebec. Can. J. Neurol. Sci. 6: 205-208.

MORRISON, D.C. (1954). Characterization of $\alpha$-keto acids as quinoxalinols. J. Amer. Chem. Soc. 76: 4483-4485.

POURCHER, E. and BARBEAU, A. (1980). Field testing of an ataxia scoring and staging system. Can. J. Neurol. Sci. 7 : 339-344. 